Commentary

\title{
For Each a Road
}

\author{
Diego E. Berman \\ Department of Neurobiology, The Weizmann Institute of Science, Rehovot 76100, Israel
}

"Two roads diverged in a yellow wood / And sorry I could not travel both. . " (Frost, 1921).

It seems that memory, unlike Frost's protagonist, can tread more than one path. Tronel and Sara, as they report in this issue of Learning and Memory (see pp. 105-111, reveal that the processes of memory consolidation and reactivation of the trace upon retrieval follow two distinct avenues in the brain.

Ample evidence suggests that memories in the brain are represented by interactive cellular networks that express internal experience-dependent representations (Dudai 1989). These distributed networks, embodied in multiple regions of the brain, may interact, following specific patterns achieved through years of evolution, to subserve the multiple stages in the life of a memory. For example, the processes of acquisition and consolidation of a particular type of memory may be achieved by the interaction of brain areas $\mathrm{A}, \mathrm{B}$, and $\mathrm{C}$, while retrieval, or extinction, of this same memory, could be accomplished by the activation of areas $\mathrm{A}, \mathrm{D}, \mathrm{E}$, and $\mathrm{F}$.

By using an odor discrimination task in rats, Tronel and Sara have investigated the various brain regions that become simultaneously activated during the postacquisition consolidation period and during memory reactivation upon retrieval. To visualize the activation of the specific areas, the authors combined the behavioral task with a tool for determining activity-induced changes in neurons: immunohistochemical staining of the neuronal activity-regulated protein c-fos (product of the immediate early gene $c$-fos). In short, the authors trained rats to identify and discriminate a particular odor (almond), and associate it with a reward (a piece of tasty crispy cereal). This type of learning is rapidly acquired and does not involve fear or acute stress. By poking its nose into a hole in a sponge impregnated with the target odor, the rat recovers the tasty reward. Either ninety minutes after the completion of training or after the retrieval trial (which consisted of one reinforced trial 24 hours after training), c-fos immunoreactivity was monitored simultaneously throughout different brain regions.

The authors analyzed several brain areas previously known to be critical to various different types of learning tasks. Among others, these areas included the frontal cor-

E-MAIL diego.berman@weizmann.ac.il; FAX (+972)-8-9344131.

Article and publication are at http://www.learnmem.org/cgi/doi/ $10.1101 / \mathrm{lm} .50202$. tex, the amygdala, the piriform cortex, the hippocampus, and the lateral habenula ( $\mathrm{LH}$, an integration site for sensorymotor and affective information output). Interestingly, these areas were differentially turned on by the training and the retrieval experiences. Learning the odor discrimination task led to an increase in the number of c-fos-positive cells in the frontal cortex (prelimbic and ventrolateral orbital cortex) and in the basolateral amygdala. On the other hand, animals that were exposed to the retrieval situation showed a strong c-fos signal mainly in the LH. c-fos immunoreactivity in the hippocampus after postacquisition consolidation and after retrieval, intriguingly, was lower than expected. However, lesions to the hippocampus have been shown to be ineffective in inducing deficits in simple odor discrimination tasks (Bunsey and Eichenbaum 1996). By running unpaired control animals, the authors also importantly show that the c-fos increment in the particular brain regions is specific to the association between the target odor and the reward, and not merely due to the exploration of the environment nor the processing of the sensory information.

Tronel and Sara's results suggest that there are indeed anatomically related regions in the brain that might be acting in concert during the consolidation and the reactivation period of an odor associative memory. Moreover, these two mnemonic processes, at least regarding this type of olfactory learning, seem to involve different brain circuitries. Although the particular roles of the frontal cortex, hippocampus, and amygdala in learning and memory have been partially delineated, the role of the activation of the LH after memory retrieval is still unknown. It has been shown that electrical stimulation of the LH induces noradrenaline release into forebrain regions (Kalen et al. 1989), suggesting that the LH might have an important impact on certain neuromodulatory systems reaching the forebrain during the period that immediately follows retrieval.

The interpretation of the increase in c-fos staining in the LH during reactivation after retrieval, however, is not trivial. During the retrieval trial of the odor discrimination task, animals are subjected to a reward-reinforced situation. Could the LH be involved in other parallel mnemonic processes, such as reconsolidation and/or strengthening of the initial trace, at the same time? Although animals are exposed to the same context and sensory stimuli during the retrieval

LEARNING \& MEMORY 9:97-98 @ 2002 by Cold Spring Harbor Laboratory Press ISSN1072-0502/02 \$5.00

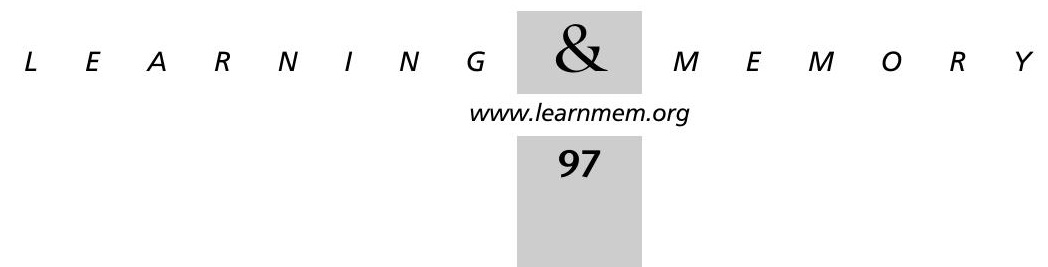


trial, the possibility that the animals may be undergoing a relearning process at the time of retrieval can not be excluded.

c-fos has been shown to be a useful marker for mapping neuronal activity (Sagar et al. 1988). However, it is as yet unknown whether and how c-fos is involved in the long-term modifications associated with the activated neurons. c-fos is a member of a family of transcription factors. Together with the Jun family proteins, c-fos forms heterodimers resulting in the formation of the AP-1 complex that regulates gene transcription (Chinenov and Kerppola 2001). Emerging evidence suggests that c-fos is essential for regulating neuronal cell survival versus death (Zhang et al. 2002). The new training-induced gene products might thus lead to the regulation of cell survival processes in the activated neurons, as well as trigger the production of molecules that will be responsible for the long-term encoding of memory during the processes of consolidation, reactivation, and updating of the trace (Berman and Dudai 2001; Carew and Sutton 2001).

The results obtained by Tronel and Sara open a new window into how different brain regions interact in order to form and retrieve a specific type of memory. Evidently, the circuits involved in the initial consolidation and in the reactivation upon retrieval are different. However, there is still much to do before we can make definite conclusions about which routes a memory takes during its diverse phases. Some unanswered questions relate to the specificity of the learning task involved. More generally, are the areas differentially activated in Tronel and Sara's study limited to this type of olfactory learning? Is this activation speciesdependent? Could the LH be acting as a 'universal memory retrieval-relearning-reconsolidation unit'? Another issue to bear in mind is how the spatiotemporal pattern of activation of these same brain regions would look if assayed at different intervals after consolidation and retrieval. Would other areas beyond the ones observed in this study light up as well? But, even if just a few types of memory follow the routes described by Tronel and Sara, the concept of being able to simultaneously follow the paths activated by a memory trace is awesome.

\section{REFERENCES}

Berman, D.E. and Dudai Y. 2001. Science 291: 2417-2419. Bunsey, M. and Eichenbaum, H. 1996. Nature 379: 225-257.

Carew, T.J. and Sutton, M.A. 2001. Nat. Neurosci. 4: 769-771.

Chinenov, Y. and Kerppola, T.K. 2001. Oncogene 20: 2438-2452.

Dudai, Y. 1989. The neurobiology of memory. pp. 3-18. Oxford University Press, Oxford, UK.

Frost, R. 1921. Mountain interval. p. 9. Henry Holt and Company, New York.

Kalen, P., Lindvall, O., and Bjorklund, A. 1989. Exp. Bran. Res. 76: 239-245.

Sagar, S.M., Sharp, F.R., and Curran, T. 1988. Science 240: 1328-1331.

Tronel, S. and Sara, S. 2002, Learn. \& Mem. 9: pp. 105-111.

Zhang, J., Zhang, D., McQuade, J.S., Behbehani, M., Tsien, J.Z., and Xu, M. 2002. Nat. Genet. 30: 416-420. 


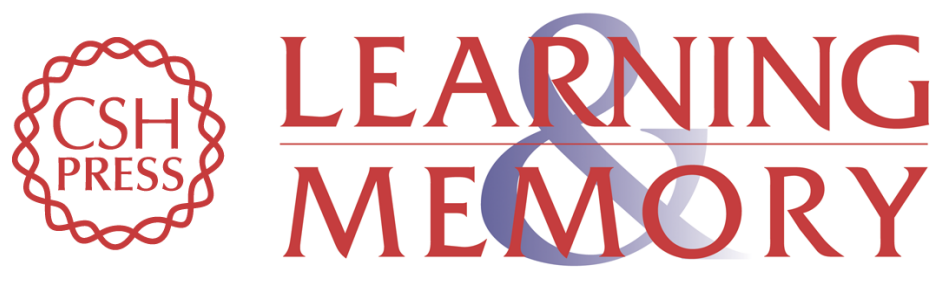

\section{For Each a Road}

Diego E. Berman

Learn. Mem. 2002, 9:

Access the most recent version at doi:10.1101/lm.50202

References This article cites 6 articles, 2 of which can be accessed free at: http://learnmem.cshlp.org/content/9/3/97.full.html\#ref-list-1

License

Email Alerting Receive free email alerts when new articles cite this article - sign up in the box at the Service top right corner of the article or click here. 